\title{
Large-scale longitudinal climate gradient causes a substantial east-west difference in feather moult extent among passerines across the entire Palearctic region
}

\author{
Yosef Kiat $^{1}$, Batmunkh Davaasuren ${ }^{2}$, Tuvshinjargal Erdenechimeg ${ }^{2}$, David Troupin ${ }^{1}$, and \\ Nir Sapir ${ }^{1}$ \\ ${ }^{1}$ University of Haifa \\ ${ }^{2}$ Wildlife Science and Conservation Center of Mongolia
}

April 28, 2020

\begin{abstract}
Large-scale spatial gradients of environmental conditions shape organisms, populations and ecosystem. Even though environmental gradients are a key research theme in macro-ecology and biogeography, the effects of large-scale, east-west, environmental gradients are largely overlooked compared with north-south gradients. Our study focused on feather moult, an important and energy demanding process in birds. By comparing Eastern and Western Palearctic populations of 21 species, we found that passerines in the Eastern and Western Palearctic differ in the number of feathers moulted. This difference is most likely the result of a large-scale climatic gradient in cold season duration and differences in time available for moulting. Eastern populations were characterized by a limited extent of feather moult that was additionally affected by migration distance and body mass. These results highlight the importance of linking annual cycle processes at the organismal level to the specific environmental conditions in the distribution range of each species.
\end{abstract}

\section{INTRODUCTION}

Environmental conditions are not equal on Earth. In many cases, a gradient of environmental conditions exists over various geographical ranges. For example, altitudinal (Roy et al. 1998; Hodkinson 2005) or latitudinal gradients (Lawson \& Weir 2014) or the distance from the ocean (Makarieva et al. 2009) may cause a gradient of environmental conditions due to changes in solar radiation and the intensity of oceanic moisture flux. These environmental gradients shape ecosystems and biodiversity at various levels, and hence, many studies have examined their effects across different ranges (Gaston 1996; Petrůet al. 2006; Alexander et al. 2011; Pellissier et al. 2018). In addition, various ecological patterns and biological rules have been applied when describing the impact of changing environmental conditions on organisms and biological systems across different gradients. Such patterns represent one of the key research themes to macro-ecologists and biogeographers (Gaston 2000; Ricklefs 2004; Steudel et al. 2012) and include the latitudinal diversity gradient (Mittelbach et al. 2007; Condamine et al. 2012), Bergmann's rule (Olson et al. 2009; Osorio-Canadas et al.2016) and Allen's rule (Allen 1877).

Due to the seasonal variation in environmental conditions, constraints imposed by the environment on animal ecology and physiology are released during specific time windows throughout the year. This allows organisms to engage in crucial season-dependent processes such as breeding at the most appropriate time. Consequently, scheduling of different annual processes and life-history traits are expected to vary over spatial gradients of environmental conditions. This is because the time windows in which season-dependent processes can occur change in relation to local environmental conditions. Additionally, differences in seasonality between regions may influence the scheduling of extended and demanding events and processes along the annual cycle, such 
as reproduction, growth, moult and migration, which usually do not overlap (Hemborget al. 2001). The ecological and biological impacts of various constraints arising from environmental conditions that vary across spatial gradients have been widely described for altitudinal (across the earth surface's height axis; e.g. , Colwell \& Lees 2000; Altshuler \& Dudley 2006) and latitudinal (across the equator-poles axis; e.g. , Mittelbach et al. 2007; McKinnon et al.2010; Lawson \& Weir 2014) rather than longitudinal (across the eastwest axis; but see Murray et al. 2004; Han et al.2011) gradients. The overlooked change in environmental conditions across longitudinal gradients is surprising due to the extreme change in climatic conditions over this axis in many parts of the world, for example, in the Eurasian Palearctic biogeographic zone (Seebohm 1901; Walter et al. 1975). The spatial climatic gradient of the Palearctic region is characterized mainly by the duration of the cold season and its intensity (longer duration and colder temperatures in the east than in the west for a given latitude; Figure 1). This gradient may affect the annual cycle scheduling of fundamental seasonal processes, the time available for growth and development and the nature of various constraints on organisms, populations, species and ecosystems. Yet, to the best of our knowledge, no empirical data have demonstrated this effect, to date.

In this study, we test a continental longitudinal effect across the Palearctic biogeographic zone, which stretches over Eurasia, on wing-feather moult, an important process in the yearly cycle of passerine birds (Jenni \& Winkler 1994). Among passerine species, moult strategies are shaped mainly by time constraints during the annual cycle, in which long periods of breeding, migration and feather moults take place (Barta et al. 2006, 2008; Kiat et al. 2019a). The scheduling of these extended and energetically demanding activities is determined by environmental conditions and the timing of the other annual cycle events during the year, as these activities usually do not overlap. For example, in migratory birds, breeding takes place after spring migration is completed, and feather moult starts typically only after breeding (Jenni \& Winkler 1994). Nevertheless, not only is the start time of each activity influenced by scheduling constraints, but so is the overall duration. Specifically, variation in the duration of feather moulting is expected to affect additional properties of the moult process (Kiat et al. 2019a).

Among passerine species, one of the common strategies for dealing with time constraints is a reduction in moult extent (number of moulted feathers) during the first year of the life (Bojarinova et al.1999; Kiat \& Sapir 2017). First-year birds are known to be particularly sensitive to time constraints (Marchetti \& Price 1989; Hanson \& Coss 1997), and consequently, partial moult is common among first-year individuals (Jenni \& Winkler 1994; Kiat \& Sapir 2017). Generally in passerines, the moult during the first year of life is intended to replace poor-quality nest-grown feathers with higher-quality feathers. Further, in many species, feather moulting changes the plumage of the bird such that it gains an adult-like appearance (Jenni \& Winkler 1994; Kiat \& Izhaki 2016; but see Kiat \& Sapir 2018). Therefore, reduced moult extent at this stage of the bird's life could affect plumage functionality, including its appearance (Kiat et al. 2019b), and consequently bird attractiveness, as well as the bird's flight capacity (Bridge 2008). All of these are expected to have implications on future survival and reproduction (Senar et al. 1998; Minias \& Iciek 2013; Crates et al. 2015).

We hypothesize that the time available for moulting is longer in the Western Palearctic compared to the Eastern Palearctic due to east-west differences in the duration and intensity of the cold season (longer and colder in the east than in the west, for a given latitude) and that the longitudinal difference in the time available for moult may be a direct consequence of the difference in climate across the Palearctic region along the east-west axis. In addition, longer migration distances in species and populations that breed in the Eastern Palearctic may indirectly reduce the time available for moulting by further shortening the time available for moult in the breeding areas (Kiat et al.2019a; Briedis et al. 2020). We thus predict that feather moult duration and consequently its extent are affected by climatic conditions across a longitudinal axis and that species-specific moult extent will be greater among western populations than eastern ones. Finally, we propose that additional factors that affect the moulting process, such as latitude, which was found to negatively affect moult extent (Kiat \& Sapir 2017), or body mass, which increases moulting speed (de la Heraet al. 2009; Rohwer et al. 2009; Kiat \& Izhaki 2016), may modulate this longitudinal effect. These factors are predicted to reduce the difference in moult extent across the east-west axis because of their own 
effect on moult extent.

\section{METHODS}

\section{Study species and feather moult data collection}

The study included 21 Palearctic passerine species from the families Motacillidae ( 5 species), Cinclidae (1 species), Muscicapidae ( 5 species), Turdidae ( 2 species), Paridae (2 species), Sittidae (1 species), Laniidae (1 species), Fringillidae (3 species) and Emberizidae (1 species), which are characterized by a wide distribution range across the Palearctic biogeographic zone. For these species, we sampled the extent of feather moult in western and eastern Palearctic populations. The border between these populations was defined as the eastern border of European Russia, the Ural Mountains and the Caspian Sea (Sclater 1858; Tutin et al. 1964; Roselaar 2006). We included species for which we were able to measure at least 10 individuals for each population (Supplementary Table 1).

Data were obtained from bird skins stored in the collections of nine natural history museums: (I) Natural History Museum (Tring; UK), (II) Museum National d'Histoire Naturelle (Paris, France), (III) National History Museum of Denmark (Copenhagen, Denmark), (IV) Museum für Naturkunde (Berlin, Germany), (V) Museo Nacional de Ciencias Naturales (Madrid, Spain), (VI) Naturhistoriska Riksmuseet (Stockholm, Sweden), (VII) Natural History Museum Vienna (Vienna, Austria), (VIII) Steinhardt Museum of Natural History, Tel-Aviv University (Tel-Aviv, Israel) and (IX) the Finnish Museum of Natural History (Helsinki, Finland). Additionally, we used moult data that were collected during bird ringing activities in Israel (several sites, mainly the Jerusalem Bird Observatory, $31.78^{\circ} \mathrm{N} / 35.21^{\circ} \mathrm{E}$, and Beit She'an Valley, $32.45^{\circ} \mathrm{N} / 35.54^{\circ} \mathrm{E}$ ) and Mongolia (Khurkh Bird Ringing Station, Khurkh River Valley, Khentii, $48.28^{\circ} \mathrm{N} / 110.49^{\circ} \mathrm{E}$ ). The moult region (Eastern or Western Palearctic) of the individuals that were examined in the study was determined by the collection or sampling location or by plumage and other morphological characteristics (according to published information; (Del Hoyo et al. 2019) used to identify individuals to the subspecies level, which is confined to a certain breeding distribution range (Supplementary Table 1).

The age of each bird was determined using published plumage characteristics for passerine species (Jenni \& Winkler, 1994). Juvenile, nest-grown feathers are poorer in texture, duller and characterized by higher abrasion than those grown during the post-juvenile moult (by juveniles) or the post-breeding moult (by adults). Using these plumage characteristics, each individual was aged as either a first-/second-calendar year (post-juvenile) bird or an adult. We used specimens of all first-/second-calendar year individuals that had completed their partial, post-juvenile moult but had not yet begun their first complete moult. Therefore, data from late autumn to early summer was included in the study, with the exception of the Spotted Flycatcher (Muscicapa striata) that undergoes a complete moult during its first winter; consequently, data for this species was collected from autumn to early winter. Even though the examined specimens were collected at different dates within the sampling period, there is no expected impact of the date of collection on the recorded moult since an additional moult only occurs in the following autumn (or in winter among Spotted Flycatchers). All of the specimens that were included in this work were collected in the Palearctic region in the years 1806-2019. All data were collected by the first author from 2012-2020.

To quantify moult extent, each wing feather of each individual was classified as being either moulted or non-moulted in the post-juvenile moult. In this study, we included only individuals whose moult had ended, confirmed by the absence of signs of moult upon visual inspection of each feather. Indications of active feather moult include the presence of feathers that are short in size and those with protective peripheral sheath remains. Moult extent was determined by documenting the moult of the wing feathers using a score of 0 (non-moulted feather) or 1 (moulted feather). A total of 42 feathers were documented using this method in each individual, as follows: greater-coverts $\left(\mathrm{GC}_{1-10}\right)$, carpal-covert $(\mathrm{CC})$, alula $\left(\mathrm{Al}_{1-3}\right)$, primary coverts $\left(\mathrm{PC}_{1-9}\right)$, primaries $\left(\mathrm{P}_{1-10}\right)$, secondaries $\left(\mathrm{S}_{1-6}\right)$ and tertials $\left(\mathrm{T}_{7-9}\right)$. In addition, we measured the proportion of moulted feathers in two feather tracts, the lesser-coverts (LC) and the median-coverts (MC). These two feather tracts are characterized by numerous small and difficult to distinguish feathers, for which we estimated the proportion of the area moulted. 
For each species, we calculated the mean migration distance in each region, Eastern or Western Palearctic, and the mid-breeding (and hence mid-moulting) latitude using published distribution maps (BirdLife International and NatureServe 2014; Del Hoyo et al. 2019). The mid-breeding latitude (and mid-wintering latitude, see below) was calculated separately for each region as the average of the northernmost latitude and the southernmost latitudes of a specie's distribution range, and the mean migration distance was the distance between the mid-breeding and mid-wintering distribution areas. Due to the inaccuracy of these maps, we calculated the migration distance with an accuracy of $1000 \mathrm{~km}$. We also incorporated published data of the species' mean body mass (Dunning Jr 2007; Supplementary Table 1).

\section{Statistical analysis}

We used generalized linear modelling (GLM; family = Gamma; $\mathrm{g}(\mu \mathrm{i})=1 / \mu \mathrm{i}$; R package 'lme4'; Bates et al. 2012) to explore the effects of longitude (east or west) on the extent of moult. We also tested the possible effects of the moulting year as an independent variable due to changes in climate conditions over time (Kiat et al. 2019b). A model that included an interaction between the effects of longitude and year was also tested. Each species was tested separately, and we selected the best model based on the Akaike Information Criterion, modified for small sample sizes (AICc; Akaike 1987). A specific model was selected only if it exhibited a $\triangle \mathrm{AICc}>2.00$ compared to other models. Model selection was performed using the $\mathrm{R}$ package 'MuMIn' (Barton \& Barton 2019) and $r^{2}$ was calculated using the R package 'rsq' (Zhang 2018).

In addition, we used a comparative approach to test the effects of three independent variables that may affect bird moulting properties (de la Hera et al. 2009; Kiat \& Sapir 2017; Kiat et al. 2019a). These variables included the difference in migration distance between Western and Eastern Palearctic, the species-specific mid moulting latitude and body mass. We specifically tested their effects on the intensity of the relationship between the longitudinal effect and moult extent (dependent variable), calculated as the difference $(\Delta)$ in the extent of passerine wing moult between the Eastern and Western Palearctic. Because species traits are known to be phylogenetically conserved, and thus data from closely related species are not statistically independent, we repeated the analysis following the independent contrasts method which identifies evolutionarily independent comparisons (Felsenstein 1985). To account for phylogenetic non-independence, we conducted this analysis using Phylogenetic Generalized Least Square (PGLS) regression (Freckleton et al.2002). We examined the strength of phylogenetic non-independence using the maximum likelihood value of the scaling parameter Pagel's $\lambda$ (Pagel 1997) implemented in the R package 'caper' (Orme 2013). Pagel's $\lambda$ is a multiplier of the off-diagonal elements of the variance-covariance matrix, which provides the best fit of the Brownian motion model to the tip data and ranges between zero (no phylogenetic signal) and one (phylogenetic signal that depends on branch lengths as in the analysis of phylogenetically independent contrasts). We then corrected for the effects of shared ancestry using the maximum likelihood value of $\lambda$. The phylogenetic tree (Figure 2) was obtained from an analysis of global bird diversity (Jetz et al. 2012) using 10,000 trees that were generated from BirdTree.org (Rubolini et al. 2015). The consensus tree was built using BEAST version 1.8.4. Analyses (two-tailed, critical $a=0.05$ ) were performed using $\mathrm{R}$ (version 3.6.2; R Development Core Team 2019).

\section{RESULTS}

We measured the extent of feather moult in 21 passerine bird species that breed in the Eastern and Western Palearctic regions $(\mathrm{n}=3126$ individuals; Figure 2 and Supplementary Table 1$)$ using skin specimens stored in nine natural history museum collections as well as live individuals examined in the field. We found that partial post-juvenile moult is more extensive in the Western Palearctic than in the Eastern Palearctic region (Figure 3 and Supplementary Figure 1). In 13 of the 21 species examined, the selected models showed a longitudinal effect on moult extent ([?]AICc $>2.00)$; in the remaining eight species, a model that included the longitudinal effect was not selected over the other models ([?]AICc $<2.00$; Supplementary Table 2).

By applying Phylogenetic Generalized Least Square (PGLS) regression using global bird phylogeny (Jetz et al. 2012), we found that the difference between moult extent in the Eastern and Western Palearctic regions is affected by species-specific differences in migration distance (between Eastern and Western Palearctic 
populations of each species) and body mass, but not by moult latitude (Figure 4 and Table 1 ). The longer migration distance in the Eastern Palearctic, probably as a result of the longer and colder winter in this region (Figure 1), caused a generally less extensive moult among passerines. In addition, high body mass was correlated with a low difference in moult extent between the Eastern and Western Palearctic regions. We conclude that these two factors differently affect the extent of moult in the Eastern and Western Palearctic; while the difference in migration distance increases the longitudinal difference in post-juvenile moult extent, body mass decreases it.

\section{DISCUSSION}

Large-scale spatial gradients in environmental conditions may affect organisms and ecosystems at different levels (Gaston 1996, 2000; Mittelbach et al. 2007; Steudel et al. 2012). In this study, we examined the effects of changes in environmental conditions, especially climatic conditions including the duration of the breeding and the post-fledging moulting period at high latitudes (Figure 1), on feather moult, a critically important process in the avian yearly cycle, with implications for plumage performance (Jenni \& Winkler 1994; Bartaet al. 2008). Our results suggest a reduced moult extent (number of moulted feathers) by juveniles of most of the tested species in the Eastern Palearctic compared to the Western Palearctic (Figure 3, Supplementary Table 2 and Supplementary Figure 1). In addition, we found that the change in moult extent across the Palearctic's longitudinal axis was modified by migration distance (between east and west) and by body mass (Figure 4 and Table 1). For a given latitude, the cold season is longer and colder in the east than in the west (Seebohm 1901; Walteret al. 1975; Figure 1). As a result, the migration distance in the Eastern Palearctic is longer (Supplementary Table 1) and breeding occurs later. Consequently, the time that is available for moulting in this region is shorter than in the Western Palearctic (Figure 5). Among juvenile passerines, the extent of wing feather moult is known to be largely affected by time availability (Kiat \& Izhaki 2016; Kiat \& Sapir 2017), explaining why the number of moulted wing feathers in the Eastern Palearctic was lower. We note that a spatial difference in feather moult timing between east and west populations was previously documented among Neotropical migrant passerines (Rohwer et al.2005). This difference was attributed to differences in precipitation and climate over a spatial scale of $\sim 3500 \mathrm{~km}$. To the best of our knowledge, our work is the first to document a difference in a life-history process across the entire Palearctic biogeographic zone $(\sim 7500 \mathrm{~km})$.

\section{The implications of partial moult}

Partial replacement of juvenile, nest-grown wing feathers during the first year of life is a common strategy among passerines due to constraints involving available time for moulting or food resources that must be acquired for this process (Jenni \& Winkler 1994; Kiat \& Izhaki 2016). These constraints can occur in extremely northern moult areas (Kiat \& Sapir 2017) or as a result of long-distance migration (Kiatet al. 2019a), higher body mass (de la Hera et al. 2009; Kiat \& Izhaki 2016) or later hatching dates (Bojarinova et al.1999). These effect are more severe for juvenile than for adult birds due to the juveniles' lower foraging proficiencies (Marchetti \& Price 1989) and anti-predator capabilities (Hanson \& Coss 1997; Rajalaet al. 2003). Partial moult affects bird appearance and thereby may affects sexual and social interactions. As a result, juveniles can be easily identified by their partial moult and nest-grown feathers, which signal their low competitive abilities (Grant 1990). An extensive partial moult may increase the attractiveness of males during the first breeding season and may positively affect bird fitness through sexual selection. However, individuals that moult extensively and consequently have a more adult-like appearance may also be subjected to more aggressive behavior from competing adults (Senar et al. 1998).

\section{The global warming analogy}

Many studies have examined the influence of various environmental factors over large-scale biogeographic gradients. These include the influence of latitude (Mittelbach et al. 2007; Lawson \& Weir 2014), altitude (Roy et al. 1998; Hodkinson 2005) or longitude (Füreder et al. 2005; Dunn et al. 2006; Finlay et al. 2011); however, large-scale longitudinal effects have only rarely been investigated thus far. Our results demonstrate the importance of considering longitudinal effects in studies of biological processes that depend on environmental 
conditions across biogeographic zones. Specifically, within the Palearctic, there are substantial differences in the climatic conditions along a longitudinal axis which calls for further studies of the implications of this spatial climatic pattern.

We note that there are several similarities between the longitudinal effects that have been revealed in our work and those described in studies of global climate change. These similarities include earlier arrival to the warmer Western Palearctic breeding areas compared to the Eastern Palearctic ones, similar to the earlier arrival to breeding areas in recent, warmer years, compared to historic arrival dates (Møller et al. 2010; Tomotani et al. 2018). In addition, the larger moult extent during the first year of life in Western Palearctic passerine populations compared to Eastern Palearctic populations (current study) resembles the higher moult extent found in recent years compared to the past (Kiat et al. 2019b). Moreover, migration distance is shorter in the Western Palearctic compared to the Eastern Palearctic, and this distance is even shorter as a result of the global climate warming (Visser et al. 2009; Pulido \& Berthold 2010). Therefore, understanding longitudinal and large-scale spatial gradients of biological phenomena that result from climatic conditions may improve our understanding of various impacts attributed to global climate change on avian life-history patterns and the evolution of annual-routine scheduling.

\section{Directions for future study}

We propose future research directions to improve our understanding of the impact of the longitudinal environmental gradient across the Palearctic region on organisms, populations, species, communities and ecosystems: We hypothesize that biogeographic and macro-ecological patterns that were found over latitudinal gradients, for example, species diversity (Mittelbach et al. 2007; Condamine et al. 2012) and body size (Bergmann's rule; Olson et al. 2009), may also hold true across the Palearctic longitudinal gradient. Consequently, we call for broad examination of longitudinal gradients in a variety of taxonomic groups, communities, food-webs and ecosystems, Specifically, we hypothesize that this environmental gradient also affects various properties of bird migration (Briedis et al.2020), including migration distance, direction, timing and over-wintering areas of different migratory populations and species across the Palearctic.

\section{Conclusions}

Environmental conditions on Earth have specific spatial and temporal attributes that can have immense influence on biological systems. Understanding how environmental gradients shape various biological processes on Earth can improve our understanding of organismal life-history and annual-routine scheduling of different activities such as migration, feather moult and breeding, as well as their evolutionary development. Furthermore, this improved understanding can also help us predict future responses to changes that may occur on the planet. In this study, we focused on moult, an important process in the avian yearly cycle, and how this process may be shaped by an environmental longitudinal gradient, a seldom studied, large-scale environmental factor. Our findings highlight the importance of linking the evolution of annual cycle processes at the organismal level to the environmental conditions to which the organism is exposed. We propose that moult extent decreases as a response to the more extensive and colder winter in the Eastern Palearctic compared with the Western Palearctic. Consequently, this work exemplifies the importance of integrating biogeography and climatology to enhance our understanding of biological patterns and their causes over large spatial scales.

\section{ACKNOWLEDGMENTS}

This research received support from the SYNTHESYS Project http://www.synthesys.info/ which is financed by European Community Research Infrastructure Action under the FP7 "Capacities" Program. We would like to thank H. V. Grouw and M. Adams from the Natural History Museum (Tring; UK), J. Fuchs and V. Bouetel from the Museum National d'Histoire Naturelle (Paris, France), K. Thorup, J. B. Kristensen and N. Manniche from the National History Museum of Denmark (Copenhagen, Denmark), S. Frahnert, P. Eckhoff and M. Voß from the Museum für Naturkunde (Berlin, Germany), J. B. Rodriguez and J. Cabarga from the Museo Nacional de Ciencias Naturales (Madrid, Spain), U. Johansson and I. Bisang from the Naturhistoriska Riksmuseet (Stockholm, Sweden), A. Gamauf and A. Hille from the Natural History Museum Vienna (Vienna, 
Austria), D. Berkowic and A. Belmaker from the Steinhardt Museum of Natural History (Tel-Aviv, Israel), and A. Aleixo and S. Sainio from the Finnish Museum of Natural History (Helsinki, Finland). Thanks to volunteers who helped with fieldwork and to Eli Haviv for his help with figures preparation.

\section{Data Availability Statement}

The data that support the findings of this study are available as supplementary files.

\section{REFERENCES}

Akaike, H. (1987). Factor analysis and AIC. Psychometrika, 52, 317-332.

Alexander, J.M., Kueffer, C., Daehler, C.C., Edwards, P.J., Pauchard, A., Seipel, T., et al. (2011). Assembly of nonnative floras along elevational gradients explained by directional ecological filtering.Proc. Natl. Acad. Sci. , 108, 656-661.

Allen, J.A. (1877). The influence of physical conditions in the genesis of species. Radic. Rev. , 1, 108-140.

Altshuler, D.L. \& Dudley, R. (2006). The physiology and biomechanics of avian flight at high altitude. Integr. Comp. Biol. , 46, 62-71.

Barta, Z., Houston, A.I., McNamara, J.M., Welham, R.K., Hedenström, A., Weber, T.P., et al. (2006). Annual routines of non-migratory birds: optimal moult strategies. Oikos , 112, 580-593.

Barta, Z., McNamara, J.M., Houston, A.I., Weber, T.P., Hedenström, A. \& Fero, O. (2008). Optimal moult strategies in migratory birds.Philos. Trans. R. Soc. London B Biol. Sci. , 363, 211-229.

Barton, K. \& Barton, M.K. (2019). Package 'MuMIn.' R Packag. version , 1, 1-75.

Bates, D., Maechler, M., Bolker, B., Walker, S., Christensen, R.H.B., Singmann, H., et al. (2012). Package 'Ime4.' R Packag. version, 1-122.

BirdLife International and NatureServe. (2014). Bird species distribution maps of the world . BirdLife International, Cambridge, UK and NatureServe, Arlington, USA.

Bojarinova, J.G., Lehikoinen, E. \& Eeva, T. (1999). Dependence of postjuvenile moult on hatching date, condition and sex in the Great Tit.J. Avian Biol. , 30, 437-446.

Bridge, E.S. (2008). How does imping affect wing Performance? J. Wildl. Rehabil. , 29, 4-9.

Briedis, M., Bauer, S., Adamík, P., Alves, J.A., Costa, J.S., Emmenegger, T., et al. (2020). Broad-scale patterns of the Afro-Palaearctic landbird migration. Glob. Ecol. Biogeogr.

Colwell, R.K. \& Lees, D.C. (2000). The mid-domain effect: geometric constraints on the geography of species richness. Trends Ecol. Evol. , 15, 70-76.

Condamine, F.L., Sperling, F.A.H., Wahlberg, N., Rasplus, J. \& Kergoat, G.J. (2012). What causes latitudinal gradients in species diversity? Evolutionary processes and ecological constraints on swallowtail biodiversity. Ecol. Lett. , 15, 267-277.

Crates, R.A., Sheldon, B.C. \& Garroway, C.J. (2015). Causes and consequences of individual variation in the extent of post-juvenile moult in the blue tit Cyanistes caeruleus (Passeriformes: Paridae).Biol. J. Linn. Soc. , 116, 341-351.

Dunn, R.R., Colwell, R.K. \& Nilsson, C. (2006). The river domain: why are there more species halfway up the river? Ecography (Cop.). , 29, 251-259.

Dunning Jr, J.B. (2007). CRC handbook of avian body masses . CRC press, Florida.

Felsenstein, J. (1985). Phylogenies and the comparative method.Am. Nat. , 125, 1-15. 
Fick, S.E. \& Hijmans, R.J. (2017). WorldClim 2: new 1-km spatial resolution climate surfaces for global land areas. Int. J. Climatol. , 37, 4302-4315.

Finlay, J.C., Hood, J.M., Limm, M.P., Power, M.E., Schade, J.D. \& Welter, J.R. (2011). Light-mediated thresholds in stream-water nutrient composition in a river network. Ecology , 92, 140-150.

Freckleton, R.P., Harvey, P.H. \& Pagel, M. (2002). Phylogenetic analysis and comparative data: a test and review of evidence. Am. Nat. , 160, 712-726.

Fureder, L., Wallinger, M. \& Burger, R. (2005). Longitudinal and seasonal pattern of insect emergence in alpine streams. Aquat. Ecol. , 39, 67-78.

Gaston, K.J. (1996). Biodiversity-latitudinal gradients. Prog. Phys. Geogr., 20, 466-476.

Gaston, K.J. (2000). Global patterns in biodiversity. Nature , 405, 220-227.

Grant, B.R. (1990). The significance of subadult plumage in Darwin's finches, Geospiza fortis. Behav. Ecol. , 1, 161-170.

Han, W.X., Fang, J.Y., Reich, P.B., Ian Woodward, F. \& Wang, Z.H. (2011). Biogeography and variability of eleven mineral elements in plant leaves across gradients of climate, soil and plant functional type in China. Ecol. Lett. , 14, 788-796.

Hanson, M.T. \& Coss, R.G. (1997). Age differences in the response of California ground Squirrels (Spermophilus beecheyi) to avian and mammalian predators. J. Comp. Psychol. , 111, 174.

Hemborg, C., Sanz, J. \& Lundberg, A. (2001). Effects of latitude on the trade-off between reproduction and moult: a long-term study with pied flycatcher. Oecologia , 129, 206-212.

Hijmans, R.J. \& van Etten, J. (2016). raster: Geographic data analysis and modeling. R Packag. version, 2 .

Hodkinson, I.D. (2005). Terrestrial insects along elevation gradients: species and community responses to altitude. Biol. Rev. , 80, 489-513.

Del Hoyo, J., Elliott, A., Sargatal, J., Christie, D.A. \& de Juana, E. (2019). Handbook of the birds of the world alive . Lynx Edicions, Barcelona.

Jenni, L. \& Winkler, R. (1994). Moult and ageing of European passerines . A\&C Black, London.

Jetz, W., Thomas, G.H., Joy, J.B., Hartmann, K. \& Mooers, A.O. (2012). The global diversity of birds in space and time. Nature, 491, 444-448.

Kiat, Y. \& Izhaki, I. (2016). Why renew fresh feathers? Advantages and conditions for the evolution of complete post-juvenile moult. J. Avian Biol. , 47, 47-56.

Kiat, Y., Izhaki, I. \& Sapir, N. (2019a). The effects of long-distance migration on the evolution of moult strategies in Western-Palearctic passerines. Biol. Rev. , 94, 700-720.

Kiat, Y. \& Sapir, N. (2017). Age-dependent modulation of songbird summer feather moult by temporal and functional constraints. Am. Nat. , 189, 184-195.

Kiat, Y. \& Sapir, N. (2018). Life-history trade-offs result in evolutionary optimization of feather quality. Biol. J. Linn. Soc. , 125, 613-624.

Kiat, Y., Vortman, Y. \& Sapir, N. (2019b). Feather moult and bird appearance are correlated with global warming over the last 200 years.Nat. Commun. , 10, 1-7.

de la Hera, I., Diaz, J. a., Perez-Tris, J. \& Telleria, J.L. (2009). A comparative study of migratory behaviour and body mass as determinants of moult duration in passerines. J. Avian Biol. , 40, 461-465. 
Lawson, A.M. \& Weir, J.T. (2014). Latitudinal gradients in climatic-niche evolution accelerate trait evolution at high latitudes.Ecol. Lett. , 17, 1427-1436.

Makarieva, A.M., Gorshkov, V.G. \& Li, B.-L. (2009). Precipitation on land versus distance from the ocean: evidence for a forest pump of atmospheric moisture. Ecol. Complex. , 6, 302-307.

Marchetti, K. \& Price, T. (1989). Differences in the foraging of juvenile and adult birds: the importance of developmental constraints. Biol. Rev. , 64, 51-70.

McKinnon, L., Smith, P.A., Nol, E., Martin, J.L., Doyle, F.I., Abraham, K.F., et al. (2010). Lower predation risk for migratory birds at high latitudes. Science (80-. ). , 327, 326-327.

Minias, P. \& Iciek, T. (2013). Extent and symmetry of post-juvenile moult as predictors of future performance in Greenfinch Carduelis chloris. J. Ornithol. , 154, 465-468.

Mittelbach, G.G., Schemske, D.W., Cornell, H. V, Allen, A.P., Brown, J.M., Bush, M.B., et al. (2007). Evolution and the latitudinal diversity gradient: speciation, extinction and biogeography. Ecol. Lett. , 10, $315-331$.

Moller, A.P., Fiedler, W. \& Berthold, P. (2010). Effects of climate change on birds . OUP Oxford.

Murray, B.R., Brown, A.H.D., Dickman, C.R. \& Crowther, M.S. (2004). Geographical gradients in seed mass in relation to climate. J. Biogeogr. , 31, 379-388.

Olson, V.A., Davies, R.G., Orme, C.D.L., Thomas, G.H., Meiri, S., Blackburn, T.M., et al. (2009). Global biogeography and ecology of body size in birds. Ecol. Lett. , 12, 249-259.

Orme, D. (2013). The caper package: comparative analysis of phylogenetics and evolution in R. R Packag. $, 5,1-36$.

Osorio-Canadas, S., Arnan, X., Rodrigo, A., Torne-Noguera, A., Molowny, R. \& Bosch, J. (2016). Body size phenology in a regional bee fauna: a temporal extension of Bergmann's rule. Ecol. Lett. , 19, 1395-1402.

Pagel, M. (1997). Inferring evolutionary processes from phylogenies.Zool. Scr. , 26, 331-348.

Pellissier, L., Albouy, C., Bascompte, J., Farwig, N., Graham, C., Loreau, M., et al. (2018). Comparing species interaction networks along environmental gradients. Biol. Rev. , 93, 785-800.

Petrů, M., Tielbörger, K., Belkin, R., Sternberg, M. \& Jeltsch, F. (2006). Life history variation in an annual plant under two opposing environmental constraints along an aridity gradient. Ecography (Cop.). , 29, 66-74.

Pulido, F. \& Berthold, P. (2010). Current selection for lower migratory activity will drive the evolution of residency in a migratory bird population. Proc. Natl. Acad. Sci. , 107, 7341-7346.

Rajala, M., Rätti, O. \& Suhonen, J. (2003). Age differences in the response of willow tits (Parus montanus) to conspecific alarm calls.Ethology , 109, 501-509.

Ricklefs, R.E. (2004). A comprehensive framework for global patterns in biodiversity. Ecol. Lett. , 7, 1-15.

Rohwer, S., Butler, L.K., Froehlich, D.R., Greenberg, R. \& Marra, P.P. (2005). Ecology and demography of east-west differences in molt scheduling of Neotropical migrant passerines. Birds Two Worlds Ecol. Evol. Migr. (R. Greenb. PP Marra, Eds.). Johns Hopkins Univ. Press. Balt. Maryl. , 87-105.

Rohwer, S., Ricklefs, R.E., Rohwer, V.G. \& Copple, M.M. (2009). Allometry of the duration of flight feather molt in birds. PLoS Biol. , 7, 1246.

Roselaar, K. (2006). The boundaries of the Palearctic region. Br. Birds , 99, 602.

Roy, K., Jablonski, D., Valentine, J.W. \& Rosenberg, G. (1998). Marine latitudinal diversity gradients: tests of causal hypotheses. Proc. Natl. Acad. Sci. , 95, 3699-3702. 
Rubolini, D., Liker, A., Garamszegi, L.Z., Møller, A.P. \& Saino, N. (2015). Using the BirdTree. org website to obtain robust phylogenies for avian comparative studies: A primer. Curr. Zool. , 61, 959-965.

Sclater, P.L. (1858). On the general geographical distribution of the members of the class Aves. J. Proc. Linn. Soc. London. Zool. , 2, 130-136.

Seebohm, H. (1901). The Birds of Siberia: A Record of a Naturalist's Visits to the Valleys of the Petchora and Yenesei . John Murray, London.

Senar, J.C., Copete, J.L. \& Martin, A.J. (1998). Behavioural and morphological correlates of variation in the extent of postjuvenile moult in the Siskin Carduelis spinus. Ibis (Lond. 1859). , 140, 661-669.

Steudel, B., Hector, A., Friedl, T., Löfke, C., Lorenz, M., Wesche, M., et al. (2012). Biodiversity effects on ecosystem functioning change along environmental stress gradients. Ecol. Lett. , 15, 1397-1405.

Tomotani, B.M., van der Jeugd, H., Gienapp, P., de la Hera, I., Pilzecker, J., Teichmann, C., et al. (2018). Climate change leads to differential shifts in the timing of annual cycle stages in a migratory bird. Glob. Chang. Biol. , 24, 823-835.

Tutin, T.G., Heywood, V.H., Burges, N.A. \& Valentine, D.H. (1964).Flora Europaea: Plantaginaceae to Compositae (and Rubiaceae). Cambridge University Press.

Visser, M.E., Perdeck, A.C., Balen, V., Johan, H. \& Both, C. (2009). Climate change leads to decreasing bird migration distances. Glob. Chang. Biol. , 15, 1859-1865.

Walter, H., Harnickell, E. \& Mueller-Dombois, D. (1975). Climate diagram maps. Ind. Ctries. Ecol. Clim. Reg. earth. Suppl. to veg. Monogr., 8.

Zhang, D. (2018). rsq: R-squared and related measures. R Packag. version , 1, 1-21.

Table 1. The effects of difference in $(\Delta)$ migration distance, mean latitude and body mass on the $\Delta$ moult extent (longitude difference between Eastern and Western Palearctic populations): list of statistical models (PGLS), statistics and Akaike Information Criterion (AICc).

\begin{tabular}{|c|c|c|c|c|c|c|c|c|c|c|}
\hline Model & $\lambda$ & $r^{2}$ & & logLik & $\begin{array}{c}\Delta \text { migration distance } \\
\text { coefficient }(\mathbf{k m})\end{array}$ & $\begin{array}{l}\text { Mean latitude } \\
\text { coefficient }\left(0^{\circ}\right)\end{array}$ & $\begin{array}{c}\text { Body mass } \\
\text { coefficient (g) }\end{array}$ & AICc & $\triangle \mathrm{AICC}$ & $\begin{array}{l}\text { Akaike } \\
\text { weight }\end{array}$ \\
\hline$\overline{\sim \Delta \text { migration distance }+ \text { body mass }}$ & 0.00 & 0.41 & 3 & -0.44 & $1.41 \mathrm{c}-04 \pm 4.29 \mathrm{c}-05$ & $N A$ & $-5.44 \mathrm{c}-03 \pm 2.51 \mathrm{c}-03$ & 8.30 & 0.00 & 0.55 \\
\hline$\sim \Delta$ migration distance & 0.00 & 0.26 & 2 & -2.88 & $1.15 \mathrm{e}-04=4.51 \mathrm{e}-05$ & NA & NA & 10.40 & 2.15 & 0.19 \\
\hline$\sim \Delta$ migration distance + body mass + mean latitude & 0.00 & 0.42 & 4 & -0.23 & $1.44 \mathrm{e}-04 \pm 4.42 \mathrm{e}-05$ & $-5.27 \mathrm{e}-03 \pm 9.10 \mathrm{e}-03$ & $-5.43 \mathrm{e}-03 \pm 2.55 \mathrm{e}-03$ & 11.00 & 2.68 & 0.15 \\
\hline$\sim \Delta$ migration distance + mean latitude & 0.00 & 0.27 & 3 & -2.71 & $1.19 \mathrm{c}-04 \pm 4.65 \mathrm{c}-05$ & $-5.43 \mathrm{c}-03 \pm 9.96 \mathrm{c}-03$ & $N A$ & 12.80 & 4.55 & 0.06 \\
\hline Null Model & 0.00 & 0.00 & 1 & -5.97 & NA & NA & NA & 14.20 & 5.88 & 0.03 \\
\hline$\sim$ body mass & 0.00 & 0.06 & 2 & -5.35 & NA & NA & $-3.19 \mathrm{e}-03 \pm 2.96 \mathrm{e}-03$ & 15.40 & 7.09 & 0.02 \\
\hline$\sim$ mean latitude & 0.00 & 0.00 & 2 & -5.96 & NA & $1.53 \mathrm{c}-03 \pm 0.01$ & $N A$ & 16.60 & 8.31 & 0.01 \\
\hline$\sim$ mean latitude + body mass & 0.00 & 0.06 & 3 & -5.35 & NA & $-9.51 \mathrm{e}-04 \pm 0.01$ & $-3.18 \mathrm{e}-03+3.05 e-03$ & 18.10 & 9.82 & 0.00 \\
\hline
\end{tabular}

\section{Figure legends}

Figure 1. Mean monthly temperature $\left({ }^{\circ} \mathrm{C}\right.$ ) in ten polygons across the longitudinal axis in the south (a) and north (b) of the Palearctic biogeographic zone. Mean monthly temperature data (spatial resolution of 30 seconds) were based on WorldClim version 2.1 climate data for 1970-2000 (Fick \& Hijmans 2017). Data processing and calculations were performed using the R package 'raster' (Hijmans \& van Etten 2016) and indicate a longer and colder winter in the Eastern Palearctic than in the Western Palearctic.

Figure 2. The phylogenetic tree of the 21 examined species included in the Phylogenetic Generalized Least Square (PGLS) analysis. The tree is based on an analysis of global bird diversity (Jetz et al. 2012) using 10,000 trees obtained from BirdTree.org (Ruboliniet al. 2015). The consensus tree was built using BEAST version 1.8.4. The tip colour represents the difference in $(\Delta)$ moult extent between the Eastern and the Western Palearctic samples $($ black $=$ maximum $\Delta$, white $=$ minimum $\Delta$ ). The scale (top left) represents 10 million years.

Figure 3. The difference in mean moult extent (number of moulted feathers) between the Eastern and Western Palearctic $(\mathrm{n}=21$ passerine species). The results indicate that moult extent among western popu- 
lations is greater than among eastern populations of the same species. The boxplots display the minimum, 1st and 3rd quartiles, median and maximum of each tested region.

Figure 4. The effect of species-specific differences in $(\Delta)$ migration distance on the difference in $(\Delta)$ moult extent between Eastern and Western Palearctic passerines among the 21 examined species $( \pm 95 \%$ confidence intervals). The results indicate a strong relationship between $\Delta$ migration distance and $\Delta$ moult extent: if an eastern population migrates a longer distance than the western population of the species, the extent of its moult decreases compared to the western population. The circled insets depict examples of $\Delta$ moult extent between Eastern and Western Palearctic regions in relation to the $\Delta$ migration distance for two species (right: Coal Tit Periparus ater, left: White Wagtail Motacilla alba ). The wing areas that are coloured depict the wing's moulted feathers while non-coloured areas represent non-moulted feathers.

Figure 5. A schematic representation of major annual processes in Eastern (inner circle) and Western Palearctic (outer circle) passerines. The information is based on published data (Del Hoyoet al. 2019) and the authors' field experience (Supplementary Note 1) and demonstrates a delay of about one month in spring and summer but not autumn events in Eastern Palearctic populations, causing a shorter post-juvenile moult period compared to the Western Palearctic. The overlap between migration, breeding and moult is represented by colour combinations.

\section{Figures}

\section{Figure 1.}

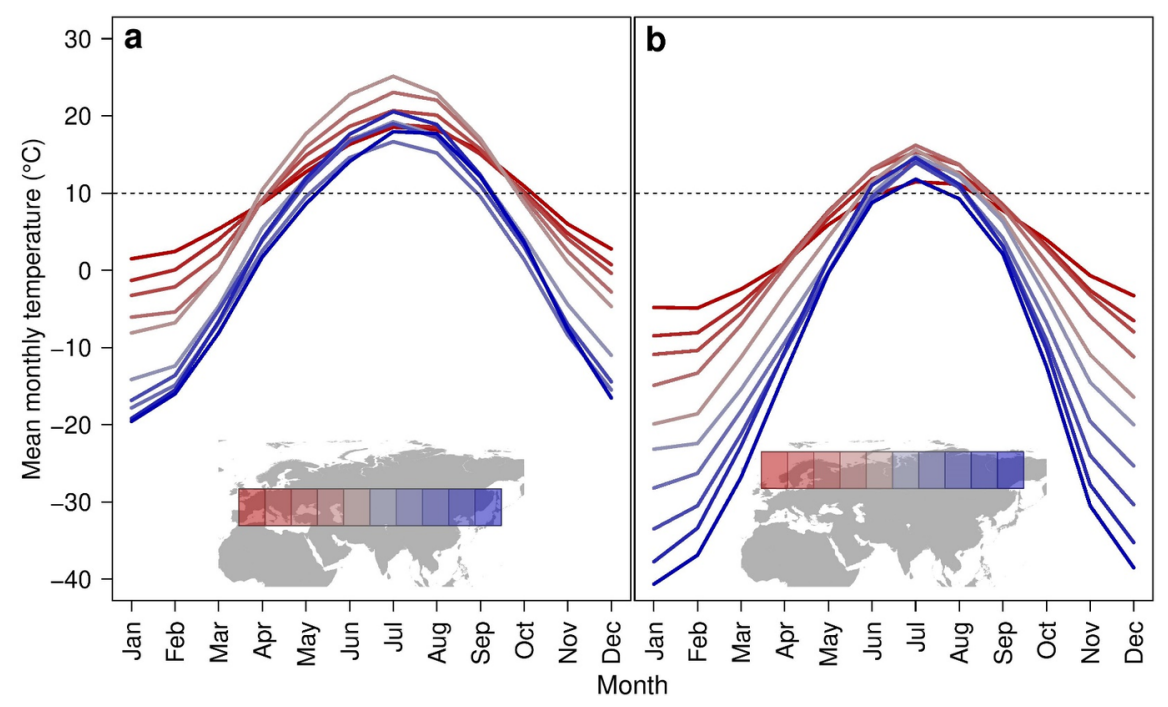

Figure 2. 


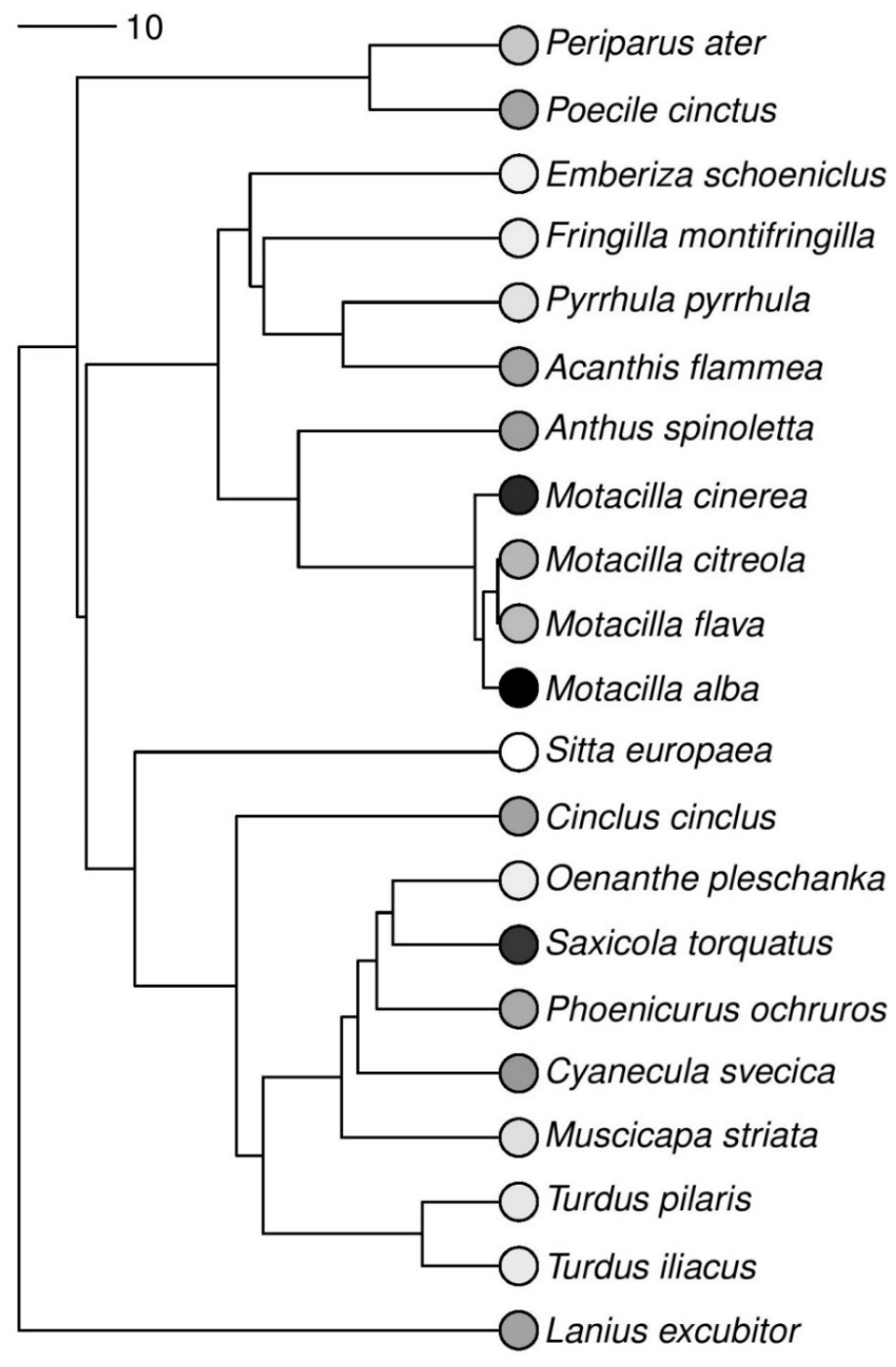

Figure 3 . 


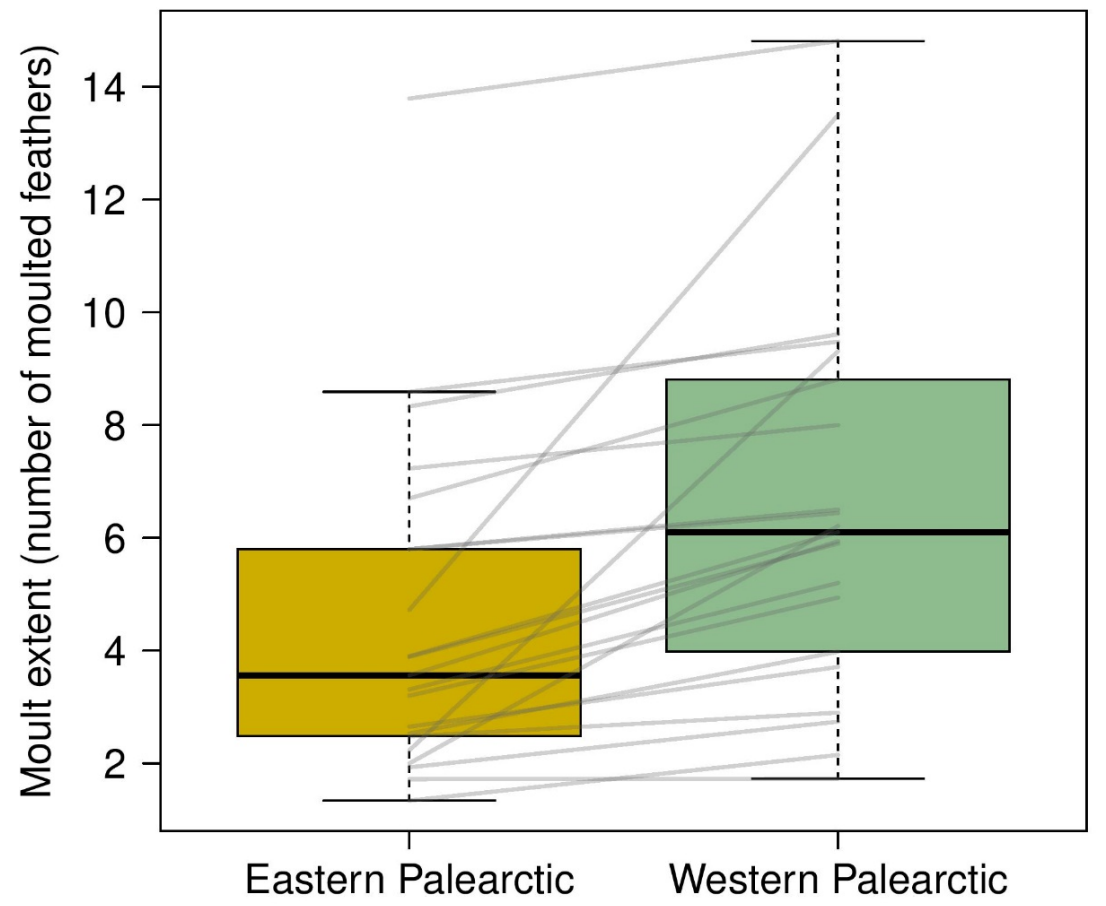

Figure 4. 


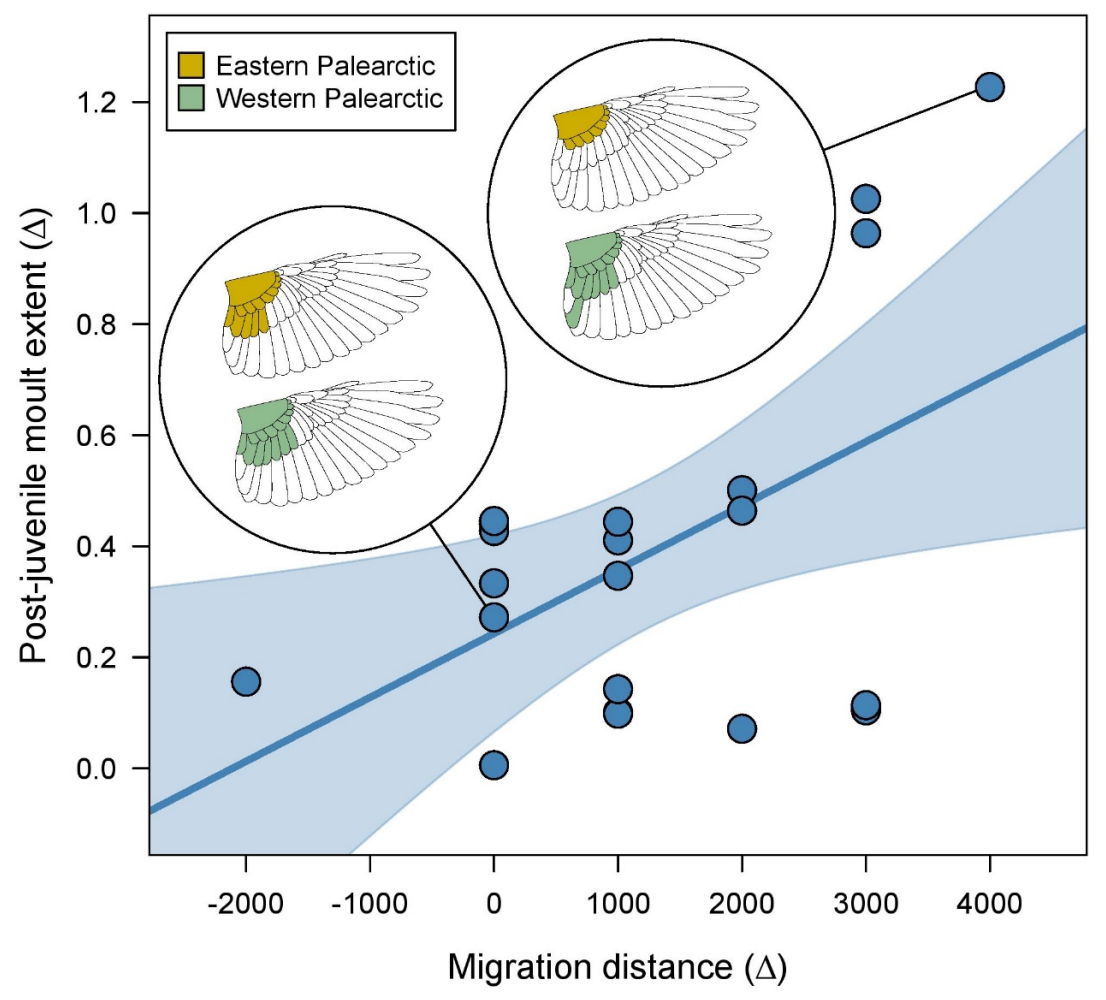

Figure 5. 


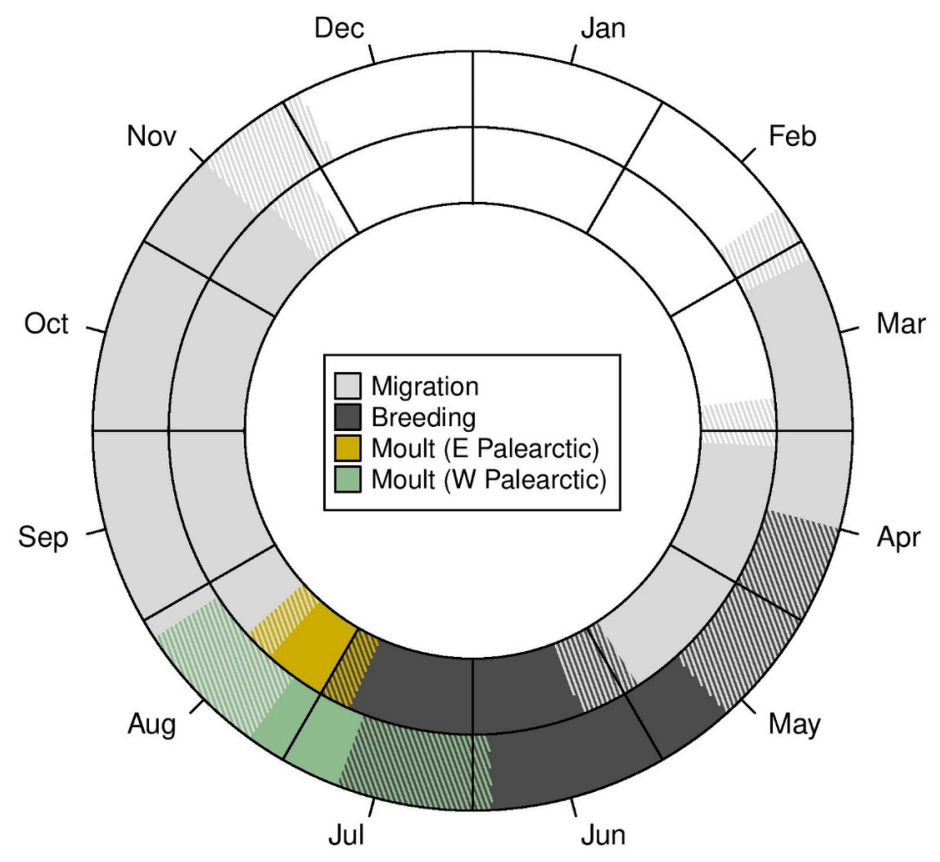

\section{Supplementary material}

Supplementary Table 1. List of the study species including information on subspecies examined, sample size, moult extent, $\Delta$ migration distance, mean latitude and body mass.

Supplementary Table 2. The effects of longitude (east or west) and year on the extent of moult: list of statistical models (GLM), statistics and Akaike Information Criterion, modified for small sample sizes (AICc) per species.

Supplementary Note 1. Supporting information for Figure 5.

Supplementary Figure 1. The difference in mean moult extent (number of moulted feathers) between Eastern and Western Palearctic birds for 21 passerine species. The boxplots display the minimum, 1st and 3rd quartiles, median and maximum of each tested region.

\section{Supplementary Figure 1.}




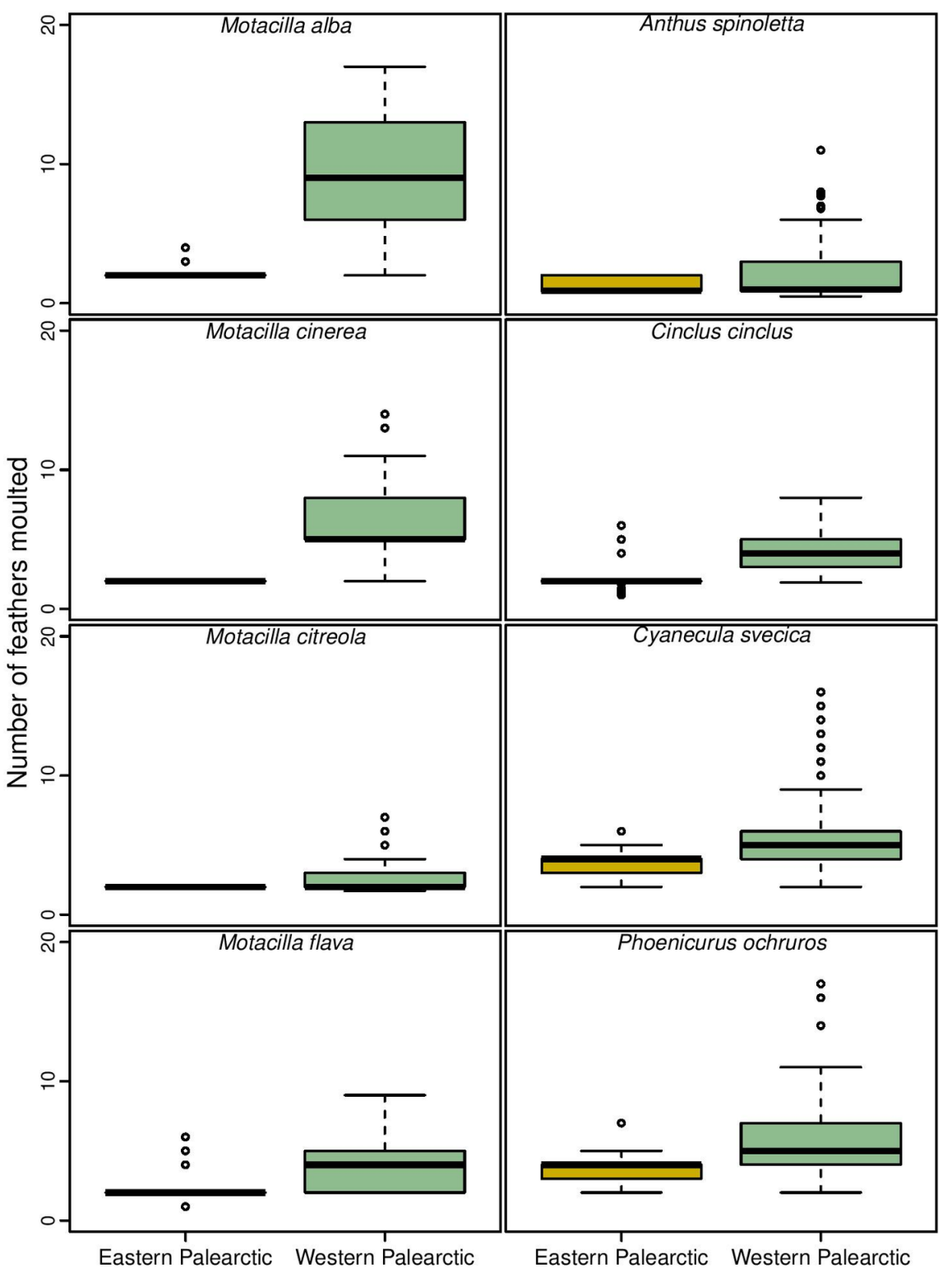




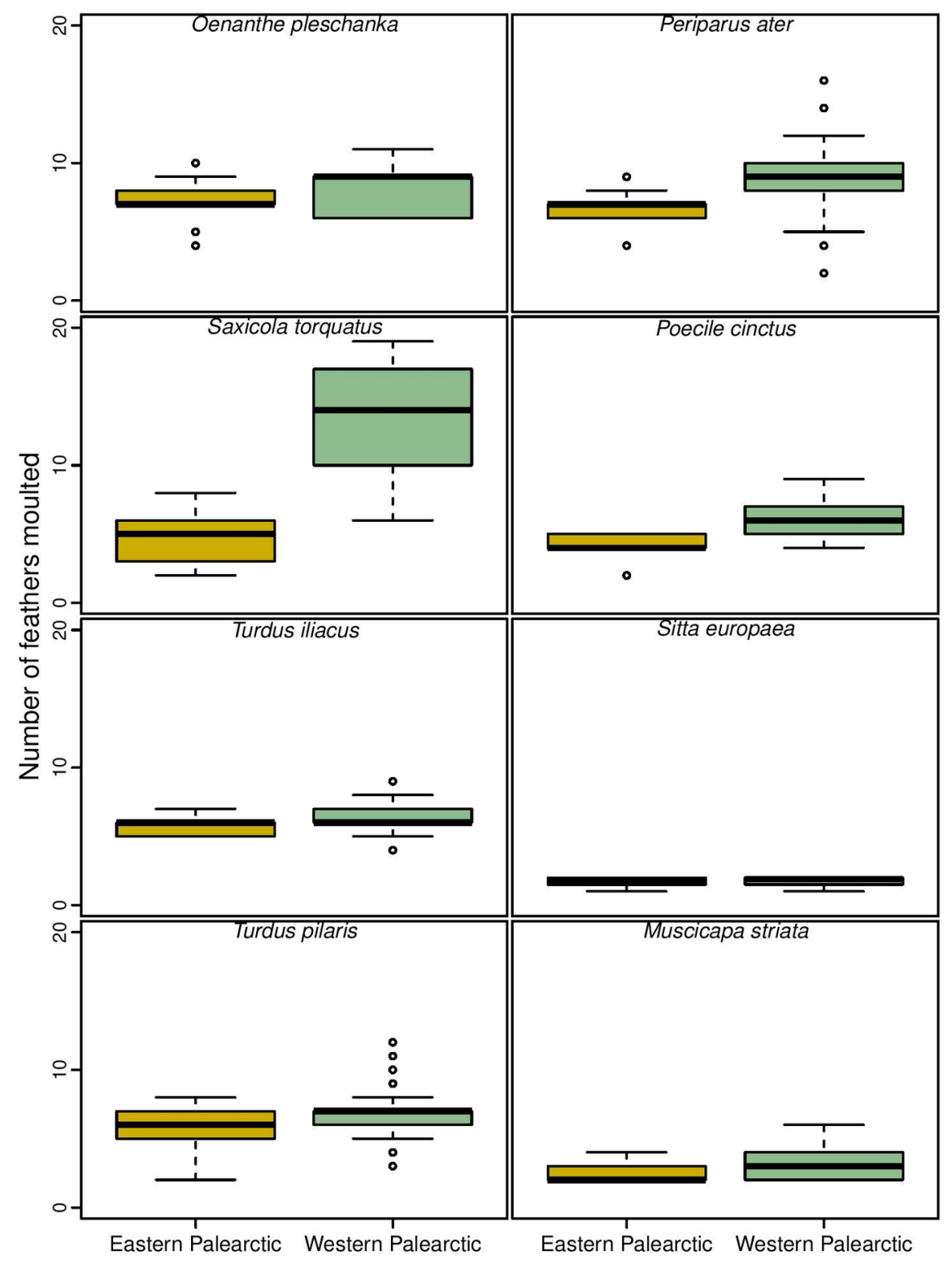




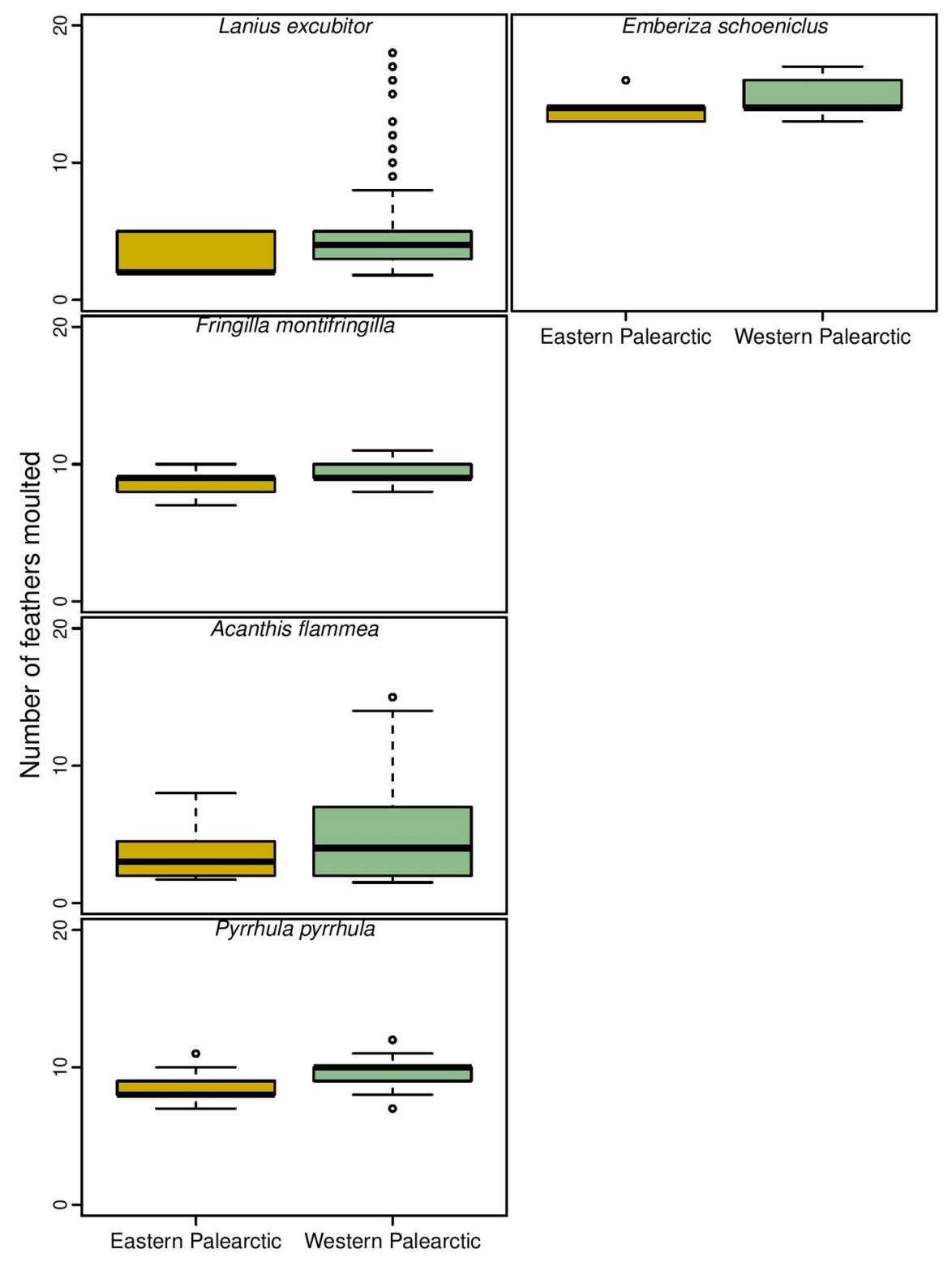

